\title{
Estéticas de la aspiración, políticas de la inclusión: glosas al desarrollo en dos saraus de Rio de Janeiro
}

\author{
Aesthetics of aspiration, policies of inclusion: \\ comments to development in two saraus of Rio de Janeiro \\ Estéticas da aspiração, políticas da inclusão: \\ comentarios ao desenvolvimento em dois saraus do Rio de Janeiro
}

Diego Bustos*

\begin{abstract}
Resumen
Durante los últimos cinco años y después de las jornadas de junio, la tradición de los saraus en Brasil experimentó un cambio cuantitativo: su incidencia aumentó exponencialmente a lo largo del territorio del país, siguiendo el ejemplo de eventos pioneros como Cooperifa. El salto también fue cualitativo: existe una versión de estos performances culturales que responde a las nuevas dinámicas socioeconómicas del país y que descubre un repertorio de significados que pueden verse como parte de una genealogía del desarrollo que siempre ha estado presente detrás de su puesta en escena. El artículo presenta, a partir del trabajo etnográfico en tres de estos eventos, un paisaje cultural que interpreta el contexto y los significados de un fenómeno que no sólo se inscribe en relación con la tradición de los saraus como el espacio por antonomasia de la cultura periférica, sino con las narrativas de desarrollo económico en la región, especialmente las puestas en práctica por los gobiernos del Partido de los Trabajadores. Comentario y ruptura, esta nueva escena de saraus arroja pistas sobre los obstáculos aún presentes a las ansias de igualdad de la nación brasilera.
\end{abstract}

Palabras-clave: saraus, periferia, desarrollo, clase media.

\begin{abstract}
During the last five years and after the days of June, the tradition of the Saraus in Brazil experienced a quantitative change: its incidence increased exponentially throughout the territory of the country, following the example of pioneering events such as Cooperifa. The jump was also qualitative: there is a version of these cultural performances that responds to the new socioeconomic dynamics of the country and that discovers a repertoire of meanings that can be seen as part of a genealogy of development that has always been present behind its staging. The article presents, from the ethnographic work in three of these events, a cultural landscape that interprets the context and meanings of a phenomenon that is not only inscribed in relation to the tradition of the saraus as the space par excellence of peripheral culture, but with the narratives of economic development in the region, especially those put into practice by the governments of the Workers' Party. Commentary and rupture, this new scene of saraus sheds clues about the obstacles still present to the desire for equality of the Brazilian nation.
\end{abstract}

Keywords: saraus, periphery, development, middle class.

\section{Resumo}

Durante os últimos cinco anos e após os dias de junho, a tradição dos saraus no Brasil experimentou uma mudança quantitativa: sua incidência aumentou exponencialmente em todo o território do país, seguindo o exemplo de eventos pioneiros como o da Cooperifa. O salto também foi qualitativo: há uma versão dessas performances culturais que responde à nova dinâmica socioeconômica do país e que descobre um repertório de significados que pode ser visto como parte de uma genealogia do desenvolvimento que sempre esteve presente por trás de sua encenação. $\mathrm{O}$ artigo apresenta, a partir do trabalho etnográfico em três desses eventos, uma paisagem cultural que interpreta o contexto e os significados de um fenômeno que não se inscreve apenas em relação à tradição dos saraus como o espaço por excelência da cultura periférica, mas com as narrativas de desenvolvimento econômico na região, especialmente aquelas colocadas em prática pelos governos do Partido dos Trabalhadores. Comentário e ruptura, essa nova cena de saraus lança pistas sobre os obstáculos ainda presentes ao desejo de igualdade da nação brasileira.

Palavras-chave: saraus, periferia, desenvolvimento, classe media.

\footnotetext{
*University of New Mexico, Albuquerque, NM, Estados Unidos. Dorcid.org/ 0000-0003-2271-9094. E-mail: dbustosd@ gmail.com
} 
El texto que sirve de prefacio a los textos de la colección Tramas Urbanas (la principal plataforma estatal de difusión editorial de la llamada literatura periférica) dicta el tono y la intención del esfuerzo editorial con el que el lector se encuentra en las páginas que le siguen: "há pouco mais de meio século, cumprimos rigorosamente nossa missão primordial, que é a de contribuir para o desenvolvimento do Brasil. E lutar para diminuir as distâncias sociais é um esforço imprescindível a qualquer país que se pretenda desenvolvido" (Vaz, 2008, p. 1). El texto devela así mismo el leitmotiv del esfuerzo crítico de este artículo: esclarecer el vínculo significante entre las narrativas de desarrollo, las diversas concepciones de igualdad que estas acarrean y la esfera cultural.

Esa primera persona corporativa (la de Petrobras, patrocinadora de la publicación) revela la ligazón histórica entre los cambios en las concepciones del desarrollo y los anhelos de igualdad de la nación brasilera. Los vaivenes experimentados por esta relación han determinado principalmente el cambio del lenguaje de las políticas públicas relacionadas con la lucha contra la desigualdad. Pero también la manera en que estas políticas interrogan el espacio ocupado por la cultura durante los diferentes ciclos de encuentro y desencuentro entre los modelos de desarrollo y democracia a lo largo de la historia reciente del país. En el presente artículo hablaré de la configuración presente de estos ciclos tomando como ejemplo la escena actual de saraus y las implicaciones que ésta tiene para la comprensión de las conexiones entre cultura e igualdad en el Brasil contemporáneo.

Los saraus me permitirán hablar alternativamente de un personaje omnipresente en el repertorio simbólico de América Latina desde sus inicios: el arribista, el que aspira a mejorar la condición social en la que nace. Representante de un linaje en las narrativas de la región desde al menos desde el siglo XIX ${ }^{1}$, este personaje es habitante ordinario o protagonista de múltiples textos, pero sobre todo de la escenificación de la cultura periférica en el seno de los saraus. Su figura contemporánea se imbrica en la red de significados determinados por el cruce de políticas públicas y producción cultural que caracterizó al gobierno del Partido dos Trabalhadores en el Brasil de los primeros años del siglo XXI. En el contexto de la variante regional del capitalismo que tiene lugar en el país durante este período, el estudio de estas subjetividades determinadas por la ascensión social se enmarca en una historia cultural más amplia. Emmanuel Wallerstein (1988, p. 98) se refería precisamente a ella cuando dijo que "no conocía de ninguna interpretación seria de nuestro mundo moderno en el que el concepto de burguesía, o alternativamente de clase media, esté ausente. Y por una buena razón. Es difícil contar una historia sin su principal protagonista".

El protagonista indiscutible de los últimos quince años en el Brasil ha sido la "Classe C" o nueva clase media, y la amalgama de fuerzas políticas, sociales y culturales que cohesionan su existencia. Parte de un fenómeno global ligado al auge de las llamadas economías en desarrollo, estas nuevas clases medias son caracterizadas más acertadamente como clases emergentes y deben su existencia en el Brasil a cambios exógenos en el mercado de productos básicos como el petróleo; a un aumento paralelo de los salarios y el crédito; y la implementación de políticas públicas de lucha contra la pobreza. Un efecto inevitable de esta historia cultural de las nuevas clases medias es el tratamiento analítico de estas políticas como bienes públicos (una infraestructura simbólica) que median las ansias de modernidad del territorio, forjando significados y subjetividades en el proceso de su formación. ${ }^{2}$

Las posibilidades de existencia de una comunidad política a partir del concepto fundamental de la aspiración es el horizonte analítico del presente texto. Los saraus se descubren así como un

\footnotetext{
${ }^{1}$ Se puede pensar por ejemplo en la picaresca fundadora del Periquillo Sarniento como antecedente de las novelas de Osorio Lizarazo en la tradición hispanoamericana, o en Memórias de um sargento de milícias, en similar posición con relación a Guia afetivo da periferia, en el caso de la tradición brasileña.

${ }^{2}$ Debido a los cambios relacionados con el cambio de gobierno producido por el golpe a Dilma Rousseff, las políticas públicas de lucha contra la pobreza han experimentado un revés producido por la crisis económica y la afectación a programas públicos como Bolsa Família. Sin embargo, aunque la tendencia producida por estos cambios es contraria al movimiento iniciado durante los gobiernos del Partido dos Trabalhadores, aún no es suficiente masivo como para contrarrestar las ganancias en términos de movilidad social que sacaron a más de treinta millones de personas de la pobreza.
} 
espacio privilegiado en donde se pueden ver escenificadas estas relaciones y los significados y subjetividades que producen. Como lo anuncia Bruce Robbins en su re-conceptualización de la evolución del estado de bienestar en las democracias occidentales a partir de las historias de ascensión social, esta infraestructura simbólica puede ser entendida desde la óptica particular de la aspiración. Así, la escenificación de estas historias, al contrario de su lectura usual, "no enseñan a ser auto-suficientes y centrarse en nuestro interés personal [...], sino que nos enseñan sobre el bien común" (Robbins, 2007, p. 5, traducción propia). Esta infraestructura simbólica, este repertorio de políticas, hace parte asimismo de un esfuerzo integral por imaginar la nación que se enmarca en los procesos modernizadores llevados a cabo en la región y que se traduce en diversos esfuerzos de intervención pública como la construcción de infraestructura (Beal, 2013, p. 15).

En el presente artículo me interesa especialmente ver cómo este esfuerzo de construcción de una comunidad política es orquestado a partir de una genealogía del desarrollo que ha definido históricamente no sólo la política pública de lucha contra la desigualdad sino el cómo se entiende el quehacer cultural desde la metáfora abarcadora de la periferia latinoamericana. Esta genealogía ha generado un repertorio de prácticas que sigue definiendo la lengua franca en la que se enmarcan políticas y acciones tendientes a la inclusión.

El concepto de periferia, entendido aquí a partir de Holston (2008, p. 156) como aspiración, como "el sueño de algún día tener una casa y un destino propios", se inscribe simbólicamente en la tensión que existe entre las fuerzas disgregadoras que asaltan las ideas de inclusión y las ansias igualitarias de la región. "La periferia está siempre cambiando, su lugar triangulado entre las variables de pobreza, ilegalidad, rápido pero precario asentamiento y urbanización. Es un lugar para el pobre que, aunque inicialmente desposeído, mejora con la autoconstrucción y la movilización política" (Holston, 2008, p. 156, traducción propia). Esta idea dinámica de la periferia, prestada de la antropología urbana, atraviesa el presente texto en su intento de inscribirse en una genealogía poco tratada en la crítica cultural latinoamericanista: la del desarrollo como discurso contradictorio de la igualdad y la de los diferentes discursos culturales alentados desde su seno. Al mismo tiempo, y como correlato inevitable de lo anterior, el presente esfuerzo quiere contribuir a la reflexión sobre ciudadanía que la producción académica reciente ha propuesto (Lehnen, 2013; Dalcastagnè, 2014) tomando como insumo analítico el mismo concepto de periferia.

\section{La tradición de los saraus}

Leila Lehnen propone definir a la cultura periférica como la que "expresa los anhelos de un segmento social que se sitúa entre las aspiraciones de ascensión social de la clase media emergente y las condiciones materiales y culturales que dificultan - cuando no impiden - esa movilidad" (2016, p. 82, traducción propia). La idea principal que atraviesa esta afirmación consiste en la relación entre los anhelos de inclusión y las características puntuales que impiden que ésta se haga realidad: en esta tensión incesante es en donde se puede ubicar el espacio significativo de la intervención cultural representada por la cultura periférica y la constante que permite historizar las relaciones entre representación e inclusión en el caso brasilero. Este artículo girará en torno a dos conceptos que son fundamentales para entender el análisis de estas relaciones en su vertiente contemporánea y en la discusión específica sobre los tres saraus que siguen a esta sección. Primero: el papel discursivo de la clase media como concepto concomitante a la relación entre el modelo económico e inclusión, sobre todo en relación con las políticas urbanas de control del territorio; y segundo: las manifestaciones de estas relaciones en términos de política pública, es decir, las políticas de acceso a la vivienda, educación (incluyendo la llamada política de cuotas), cultura (Pontos de Cultura), y las llamadas transferencias de renta condicional (conditional cash transfers). Veremos que los dos órdenes problematizan la idea de periferia que ha sido utilizada para encuadrar el fenómeno de saraus en particular y de cultura periférica en general.

Dentro del movimiento conocido como cultura periférica, tal vez ningún otro fenómeno comente de manera más sugerente las transformaciones políticas y socioeconómicas de la primera década del 
siglo XXI brasilero que la escena de los llamados saraus. Estos son eventos culturales que dan cabida a diversas manifestaciones artísticas (poesía, música y performance) en diferentes lugares públicos y privados de las ciudades brasileras, congregando cada vez un público fiel.

El concepto existe en la tradición latinoamericana y brasilera desde el siglo XIX, cuando invocaba así mismo las maneras de reunión de una asamblea que lo hace para expresarse artísticamente. Saraus fueron, por ejemplo, las tertulias literarias que en la mejor tradición de los cafés literarios europeos pulularon en las ciudades latinoamericanas a principios del siglo XX. Así, el sarau ha sido considerado como punto de encuentro y debate del discurso público, de especial relevancia en los procesos de construcción de nación en los siglos XIX y XX (Pantoja, 2002). Las tertulias, cenáculos o saraus fueron los espacios desde donde las clases dirigentes imaginaban el discurso público de las nacientes repúblicas de América Latina.

En el Brasil, Pivetta y Pellizaro (2017) trazan una genealogía que ubica en el siglo XIX los orígenes elitistas del sarau y rastrean sus múltiples mudanzas en los subsiguientes periodos modernistas, en el movimiento contracultural de la poesía marginal, ${ }^{3}$ y finalmente en el escenario de saraus del Brasil contemporáneo. Los autores asumen "que la forma asumida por el sarau acompaña las dinámicas sociales, haciendo evidente, en cualquier época, las múltiples relaciones que se establecen entre arte y sociedad, estética y política" (p. 67, traducción propia). Por eso mismo, según Ángel Rama (1984, p.161), estos espacios se consolidaron en América Latina como escenario de disputa por la representación de los nuevos segmentos sociales que a principios del siglo $\mathrm{XX}$ venían en ascenso y que encontraban en las tertulias, pero también en las dinámicas del mercado editorial, espacios a ser copados y disputados. El fenómeno reflejaba y comentaba los salones literarios que pulularon en la Europa de la revolución burguesa y la consolidación de comunidades nacionales. Pivetta y Pellizaro $(2017$, p. 66) precisan en ese sentido que fue la corte portuguesa la que importó el sarau al Brasil. En continuación de esta tradición, los saraus siguen comentando durante las primeras décadas del siglo XXI las transformaciones sociales de los territorios en donde se desarrollan.

En la tradición brasilera contemporánea, los saraus han cumplido un papel fundamental en la escenificación de la cultura de los territorios periféricos de las ciudades durante los primeros años del siglo XXI. El concepto decimonónico original ha sido reapropiado y resignificado como el escenario por antonomasia donde la cultura es representada con el objeto de dar voz a las diferentes poblaciones marginalizadas y su vida en los territorios periféricos de la urbe (Nascimento, 2009; Tennina, 2014). En este artículo argumento que esta reinterpretación ha sido posible sobre todo a la existencia de una tradición del desarrollo sin cuya existencia no se pueden vincular dos órdenes esenciales a su relectura periférica: la clase media y la intervención urbana.

Esta ligazón de los saraus con la tradición sobre la clase media y las dinámicas urbanas de inclusión hace pertinente encuadrar su aparición en relación con el concepto de periferia, que es entendida aquí como una categoría espacial, pero sobre todo económica y urbana. Según la definición ofrecida por Lucía Tennina refiriéndose al contexto de São Paulo, los saraus contemporáneos se pueden definir como "reuniones en bares de diferentes barrios de la periferia [de São Paulo], donde los vecinos declaman o leen textos propios o ajenos frente a un micrófono durante aproximadamente dos o tres horas" (2017, p. 86). El caso de los saraus contemporáneos ofrece una oportunidad única para pensar cómo las ideas de Rama sobre las disputas por la representación a principios del siglo XX se pueden trasladar al contexto contemporáneo brasilero, pensados como representaciones de una gramática dada del desarrollo. Como correlato esencial a esta aproximación, esta es una veta fascinante sobre los vasos comunicantes entre estudios los brasilianistas y la tradición hispanoamericana.

Las transformaciones socioeconómicas experimentadas por Brasil durante los primeros años del siglo XXI tuvieron unas consecuencias puntuales en la vida y en la representación de

\footnotetext{
${ }^{3}$ Es necesario diferenciar explícitamente en este punto a la poesía marginal surgida en los años setenta en el Brasil, en el seno de un movimiento contracultural mayormente universitario y de clase media, de la literatura marginal o periférica, que constituye el tema general de este artículo y que se identifica con la producción literaria de las periferias urbanas en el país durante los primeros años del siglo XXI. Estos significados contradictorios de lo marginal hacen deseable utilizar el adjetivo periférico para referirse al segundo fenómeno.
} 
los sectores marginales de la sociedad. En este sentido, los saraus se presentan como espacios desde donde se puede comprobar la naturaleza contradictoria de la modernización en la periferia latinoamericana. Estos espacios comentan una narrativa específica de desarrollo, inclusión y aspiración que media y moldea las prácticas de las comunidades en donde se desarrollan. En su práctica se despliegan y constatan las relaciones entre las políticas públicas puestas en marcha por los gobiernos y los modelos de aspiración que determinan algunas de las características de los espacios periféricos y su relación con el espacio social. Presento dos casos de saraus en Rio de Janeiro cuya naturaleza comenta y enriquece la relación de estos espacios con los modelos de representación del Brasil contemporáneo y sus periferias. Propongo que una lectura de la escena de los saraus desde la perspectiva de las políticas de lucha contra la pobreza enriquece la reflexión académica que se ha ocupado del tema.

El texto que sigue se divide en dos partes: en la primera hablaré del Sarau do Escritório, un sarau de Rio de Janeiro que se organiza en el centro de la ciudad y cuyo espacio de enunciación y narrativa de aspiración enriquece la escena tradicional de estos espacios; en la segunda se hablará del Sarau do Velho, organizado en el barrio Vila Aliança, en Bangú, Rio de Janeiro y cuyo locus geográfico comenta las ansias de desarrollo y democracia del país: uno de los primeros proyectos de vivienda popular aparecidos en el contexto de la Alianza para el Progreso en América Latina. Los comentarios hechos al respecto son producto de la observación participante realizada durante un lapso de tres meses, desde el doce de junio hasta el cinco de septiembre de 2017. Durante este tiempo se realizaron entrevistas y se observaron los diferentes escenarios en donde los saraus tomaron lugar.

A continuación veremos cómo los casos observados comentan y problematizan las intersecciones entre modelos de desarrollo e inclusión. Las diferentes ideas sobre clase media y territorio que se escenifican en su seno permiten historizar estas relaciones a partir de lo que Lucía Tennina (2017) identifica como la desterritorialización e internacionalización del circuito de saraus en el Brasil contemporáneo. Esto ayuda a entender el tipo de economía representacional escenificada entre las ideas de periferia y cultura durante los últimos quince años en el país.

\section{El excepcionalismo carioca: el Sarau do Escritório}

Los últimos jueves de cada mes se celebra el Sarau do Escritório en el céntrico barrio de Lapa, en Rio de Janeiro. El evento se realiza en la recientemente bautizada plaza Luana Muniz, activista que convirtió al sector en símbolo de la lucha por los derechos de la población queer. ${ }^{4}$ Un público variado se aglomera desde temprano al lado de los bares adyacentes rebosantes de turistas y transeúntes que vienen de los cuatro puntos cardinales de la ciudad para trasegar el paisaje nocturno del barrio.

El eslogan del evento, "Quem bate cartão, também faz poesía", es decir "quien marca tarjeta (quien cumple un horario laboral) también hace poesía", en conjunción con el espacio físico y simbólico en donde se lleva a cabo, sugieren un giro significativo en relación con la tradición reciente de saraus que existe en Brasil desde el inicio del siglo XXI y que surgió como el espacio cultural por antonomasia de las llamadas periferias urbanas. Esta ruptura se entiende desde el contexto de análisis basado en el sujeto reclamador de derechos que informa la producción académica publicada hasta ahora sobre el tema.

La nueva etapa en el circuito de saraus que representaría este espacio ha sido documentada también por otros trabajos académicos (Chamone, 2016) y por esfuerzos investigativos independientes. Por ejemplo, el colectivo Mufa Produções mapeó la aparición contemporánea de saraus en el área metropolitana de Rio de Janeiro, encontrando que 133 de estos eventos

\footnotetext{
${ }^{4}$ Luana Muniz llevó a cabo una labor de defensa de los derechos de diversas comunidades habitantes de Lapa. Fue la creadora del eslogan "Travesti não é bagunça” y acogió travestis, transexuales, portadores de VIH, prostitutas y habitantes de calle en un casarón en la calle Mem de Sá del barrio. Murió producto de una neumonía en mayo de 2017.
} 
funcionaban en la ciudad con una regularidad al menos mensual ${ }^{5}$. La localización geográfica de éstos se extiende por toda la ciudad, incluyendo no solamente zonas periféricas. Así mismo, el mapeo encontró que la totalidad de los eventos se anunciaban en Facebook y que cien de los saraus habían aparecido después de las jornadas de junio de 2013, lo cual plantea una interesante veta de investigación sobre la relación entre democracia y el contexto cultural del país. Recientemente, Leila Lehnen (2018) ha hablado de las posibilidades de interpretación desde la veta cultural de la crisis cuya fecha de inicio muchos identifican con las jornadas mencionadas, a partir de la publicación de antologías de poesía (i.e Golpe antologia manifesto, Vinagre, etc.). La lectura cultural del escenario de saraus que se propone en el presente artículo se contextualiza en este paisaje crítico y constituye una contribución a la producción académica reciente sobre el fenómeno.

El Sarau do Escritório es organizado por un colectivo cultural cuyos miembros no sobrepasan los treinta años y que se formaron en el teatro y las artes escénicas. El dato sobre su edad es significativo porque la mayoría de ellos obtuvo un espacio en la educación formal superior gracias a las políticas de cuotas puestas en marcha por el gobierno del Partido dos Trabalhadores durante las dos presidencias consecutivas de Luiz Inácio "Lula" da Silva. En entrevistas realizadas con miembros del colectivo, todos observaron que pertenecen a la "primera generación": es decir, fueron los primeros en sus familias en ir a la universidad.

La realización del evento fue posible gracias al consentimiento y apoyo inicial de la alcaldía de la ciudad, cuya secretaría de cultura al momento de iniciar su patrocinio en 2013 reflejaba el tipo de visión de la cultura como discurso de inclusión diseminado desde el gobierno federal. Es revelador el hecho de que el director de la secretaría en el momento de garantizar los fondos para la realización del evento era el carioca Júnior Perim, autor de Panfleto, uno de los textos fundamentales de la literatura periférica.

En oposición a otros eventos culturales similares, el Sarau do Escritório no se organiza en la periferia de la ciudad sino en uno de sus barrios más céntricos y tradicionales. En este sentido presenta un claro contraste con la ortodoxia de lo saraus originados en el contexto de São Paulo y cuyo principal representante es el de Cooperifa, liderado por el poeta Sérgio Vaz. La ubicación geográfica del evento no es el único dato contrastante de éste. En la noche del jueves 20 de julio del 2017 la programación del Sarau do Escritório rindió homenaje al vendedor local de coxinhas (un plato típico de la tradición culinaria brasilera) Magno de Sousa Marques, quien hasta esa noche había construido un pequeño imperio de ventas del popular aperitivo en el local situado en una de las calles adyacentes a la plaza donde se lleva a cabo el evento.

En la biografía que el $M C$ lee iluminado por las luces de neón que rodean el escenario (el espacio del evento toma prestada su estructura y puesta en escena de la tradición del rap) se narra cómo Magno, hijo de emigrantes del nordeste del país, recibió la receta del popular bocadillo de manos de su padre hasta perfeccionarla en el negocio en donde ahora llega a vender más de tres mil unidades cada noche. Gracias a un crédito y su compromiso emprendedor, Magno da empleo a más veinte personas. Sorprendido por el homenaje y después de escuchar impertérrito un largo elogio de su empresa, el pequeño empresario se presentó sonriente ante el público antes de leer unas palabras de agradecimiento y dar paso a las presentaciones de los músicos y poetas que intervinieron esa noche en el evento.

El proyecto económico y político del Partido dos Trabalhadores descansó en buena parte sobre la importancia dada a la emergencia de las llamadas nuevas clases medias. Según Pereira (2015, p. 7) el ingreso per cápita que había estado estancado durante las décadas anteriores en el país experimentó un crecimiento sostenido entre los años 2003 y 2011. Este desempeño se basó en el boom del mercado internacional de commodities y permitió asimismo el aumento en el crédito y el consumo interno. Adicionalmente a las cifras positivas con relación a la creación de empleo, el aumento de los salarios y el consumo, el gobierno implementó una serie de herramientas de política encaminadas a la lucha contra la desigualdad y la pobreza. El más visible de estos programas es conocido como Bolsa Família, en donde se hace una transferencia de recursos a las familias que cumplan ciertos

\footnotetext{
${ }^{5}$ Los resultados de este esfuerzo investigativo se pueden ver en: http://mufaproducoes.com/mapeamento-de-saraus-rj/
} 
requisitos relacionados con el acceso a la educación y la salud de sus hijos. Como resultado de la combinación de los anteriores factores casi cincuenta millones de personas superaron la línea de pobreza durante los primeros años del siglo XXI, engrosando la llamada Classe C. No es un fenómeno exclusivo del Brasil: tanto en Colombia, México o Perú políticas similares de transferencia de renta determinaron dinámicas parecidas.

El componente económico de este cambio estuvo aparejado por unas políticas y dinámicas culturales que se concibieron y pusieron en práctica al mismo tiempo que las transformaciones económicas que tomaban lugar. Por ejemplo, de la mano de la emergencia de la llamada literatura periférica o marginal, cuyo inicio algunos autores sitúan en la publicación en 1998 de Cidade de Deus, de Paulo Lins, y otros en la publicación de Quarto de despejo, de Carolina María de Jesús en 1960, los saraus comenzaron a organizarse y entenderse como eventos que replicaban en el espacio público un proyecto estético específico: la inserción de las poblaciones excluidas de la economía simbólica del país de una manera que evitara las representaciones estereotipadas y superficiales de estas comunidades. En ese contexto surgieron los saraus más representativos del período, siendo el más importante el mencionado de Cooperifa, surgido bajo el liderazgo de Sérgio Vaz. Así mismo políticas públicas como Cultura Viva o la implementación de los Pontos do Cultura ${ }^{6}$ surgieron durante el mismo periodo.

La dinámica representada por la aparición de la escena de saraus comenta una de las tensiones fundamentales que atraviesa el modelo de desarrollo del Partido dos Trabalhadores: la diferencia entre la igualdad de oportunidades y la de resultados. De manera esquemática, la igualdad de oportunidades se refiere a la idea de que todos los miembros de una comunidad deben compartir las mismas condiciones iniciales que les permitan perseguir la consecución de sus metas individuales. Por otro lado, la igualdad de resultados aboga por la consecución igualitaria de ciertos bienes o condiciones finales por parte de todos los miembros de una sociedad dada.

El caso del Sarau do Escritório viene a problematizar esta dualidad pues se inscribe en una lógica diferente a la de los saraus que le antecedieron: en oposición a ofrecer un espacio para la expresión de las voces dejadas a un lado en las periferias de la ciudad, inscribe su accionar en medio de uno de los barrios céntricos de Rio de Janeiro: Lapa, epicentro del resurgimiento turístico de esa parte de la urbe. Además de lo anterior, el eslogan que utiliza, "Quem bate cartão, também faz poesía", problematiza las ansias de inclusión al involucrar en su estructura un componente económico fundamental: las relaciones de trabajo como concomitantes a las relaciones de desigualdad imperantes bajo el desarrollo contemporáneo del capitalismo. Esta concepción marxista de la desigualdad, es decir, el desbalance entre quienes tienen acceso a los medios de producción y los que no, es básica para entender el tipo de intervención que propone el sarau. Es fascinante comprobar cómo éste se presenta entonces como una solución de continuidad a las contradicciones en términos de inclusión del modelo político y económico del lulismo en el Brasil contemporáneo a partir de la inclusión de una narrativa que hace patente las relaciones de trabajo en su interior.

En el Sarau do Escritório los retos presentados por el cambio del modelo fordista hacia la precarización del trabajo asalariado, junto con los retos en falta de acceso a trabajo formal (Souza y Arenari, 2010, p. 35), son problematizados e interpretados a partir de un lenguaje de emprendimiento y esfuerzo individual, representado tanto por el eslogan como por el homenaje al microempresario de coxinhas. Este lenguaje es usado para visibilizar un barrio histórico que había experimentado un periodo prolongado de decadencia urbana, y lo hace involucrando a la poesía y la música como valencia que ayude a jalonar la recuperación del territorio. Esta intervención hace patente la marca aspiracional del concepto de periferia como concomitante al modelo de desarrollo del país. El "sueño de tener un destino propio" no sólo se escenifica en la recuperación de la historia de Magno y su trayectoria empresarial y migratoria, sino también en la recuperación del espacio físico en donde se lleva a cabo el evento a partir de estos

\footnotetext{
${ }^{6}$ Cultura Viva fue el programa estatal de cultura puesto en práctica durante el gobierno del Partido dos Trabalhadores, y Pontos do Cultura fue su programa estrella. Sus objetivos estaban determinados por una idea de gestión pública que buscaba involucrar a las comunidades en la creación y difusión de productos culturales.
} 
desplazamientos: el territorio de Lapa se resignifica y revaloriza no a partir de su pasado galante sino gracias al advenimiento periférico del que es testigo. La periferia justifica un territorio en desuso a partir de su intervención.

De esta manera, el Sarau do Escritório escenifica y entrelaza en un solo lugar los conceptos de desigualdad, periferia, cultura y emprendimiento. Al hacer patente la posibilidad de que quienes trabajan como asalariados también pueden acceder a la poesía, a la cultura, bien sea como espectadores o productores, pone en entredicho las identidades que la cultura hegemónica se ha encargado de construir históricamente entre el reino de la cultura y el consumidor y productor de ésta. La mano de obra precarizada como habitante de las periferias de las ciudades y las dinámicas urbanas que se han generado a partir de esta situación contrastan con la escenificación del sarau en un barrio histórico y central de la ciudad. La centralidad de Lapa, sin embargo, es discutible en el sentido de que se trata de un territorio que experimentó un período prolongado de decadencia urbana (siendo conocido por mucho tiempo como una de las zonas de tolerancia de la ciudad) y de marginalización comparable a la de los territorios periféricos. Al traer el sarau a Lapa como manera de revigorización urbana, se traslada desde las periferias el mismo discurso usado para retomar para sí la centralidad del discurso de representación. El Sarau do Escritório realiza esta intervención de manera más radical y en consonancia con los cambios económicos recientes: a través del discurso de emprendimiento que ha determinado la aparición de las periferias y de las nuevas clases medias en el Brasil contemporáneo.

Es interesante notar que de alguna manera este gesto comenta, por ejemplo, la trayectoria vital de Carolina Maria de Jesus, quien ha sido considerada por algunos escritores y académicos como la antecesora de todo el movimiento periférico, cuando declara en su Quarto de despejo que ella escribía, precisamente, para dejar atrás la favela. Así, su obra fundacional caracteriza a la periferia, (o a la versión de ella en todo caso que representa la favela) como un lugar de paso que debe ser superado y que existe sólo porque cumple una función en la economía material y simbólica de la ciudad. Es esta última (y no la favela) el espacio al que se aspira habitar.

Esta relación problemática entre cultura y periferia es el mismo motivo detrás de la historia con que Evelina Dagnino (2005) comenta las estrategias de reclamación de derechos de una comunidad que se organizó en la Assembléia do Povo, un movimiento de favelados surgido en 1979 en Campinas, estado de São Paulo. La citada organización, que surgió alrededor del reclamo al derecho al uso de la tierra, utilizó una curiosa estrategia para entablar sus demandas: antes de empezar la movilización propiamente dicha, su primera iniciativa pública fue solicitar a los medios de comunicación locales la publicación de los resultados de una encuesta hecha por ellos mismos sobre la vida en su comunidad 7 . El objetivo de esta campaña de relaciones públicas era desvirtuar las ideas preconcebidas que la sociedad tenía con respecto a los habitantes de la favela: en vez de presentar un territorio habitado por "perezosos, marginales o prostitutas", la encuesta describía a los miembros de la comunidad como "ciudadanos decentes y trabajadores que deberían ser vistos como portadores de derechos". Esta intervención estaba destinada a proyectar una imagen de respetabilidad hacia el exterior. Es decir, antes de reclamar su derecho a la inclusión, la comunidad orquestó un mecanismo de representación que le permitiera ser vista por el resto de la sociedad sin el filtro de los estereotipos sociales, de tal manera que visibilizara la legitimidad de sus demandas al ser percibidos como un miembro deliberante lícito. El catalizador del cambio fue de nuevo un discurso de emprendimiento y avance social: la capacidad de identificarse como miembros de la clase media. Sin sorpresa, Dagnino descubre y describe ni más ni menos que la estrategia usada por los saraus al invocar el territorio habitado como productor de cultura.

La estrategia mencionada es la que atraviesa la apuesta discursiva y subjetiva de otros textos que se han ocupado de la periferia recientemente. Por ejemplo, Guia afetivo da periferia, de Marcus Vinicius Faustini. De una manera que calca las estrategias narrativas de este texto, la intervención urbana que en el centro de Lapa escenifica el Sarau do Escritório se apropia de un

\footnotetext{
${ }^{7}$ La anécdota es referida en Dagnino (2005).
} 
espacio degradado y lo reincorpora a la polis a partir de una escenificación del emprendimiento y la aspiración social. La desigualdad existente entre los asalariados y los dueños de los medios de producción se hace explícita y se problematiza al involucrar en su dinámica una subjetividad emprendedora. Esta concepción de desigualdad definida como desequilibrio de acceso a los medios de producción y por lo tanto a la posibilidad de producir plusvalía, contrasta con las ideas sobre desigualdad que informan la interpretación clásica de la escena de saraus. Éstas se estructuran a partir de las políticas de la diferencia tal como las entiende Iris Young (1990) y en la veta relacionada con el Brasil, el trabajo de la antropóloga Evelina Dagnino. En la guerra por la representación de estas comunidades, acaecida en medio de las transformaciones económicas y las crecientes demandas sociales de diferentes poblaciones marginalizadas en el territorio, la veta representada por el Sarau de Escritório viene a enriquecer y problematizar las estrategias usadas y explicitadas por el análisis mencionado. Por eso mismo permite involucrar en el análisis cultural la gramática de emprendimiento que determinó las políticas públicas de lucha contra la pobreza puestas en marcha durante el período.

Al involucrar esta gramática de emprendimiento en el cambio en las condiciones de producción donde la precarización de las condiciones laborales determina la inserción de la población al mercado laboral, el Sarau do Escritório se inscribe en una economía simbólica que desestabiliza y descubre al mismo tiempo las connotaciones incluyentes de la periferia y propone maneras de imaginar el modelo que el Brasil contemporáneo usó para lidiar con las ansias de inclusión heredadas de su pasado. Este modelo es complementario al ejemplo del Sarau do Velho, cuya intervención historicista comenta el concepto de periferia de manera complementaria y cuyo ejemplo se trata a continuación.

\section{La tradición del progreso: el Sarau do Velho y Vila Aliança}

Vila Aliança fue uno de los proyectos urbanísticos pioneros en América Latina enmarcados en la Alianza Para el Progreso, una serie de políticas de alcance hemisférico impulsadas por el gobierno de los Estados Unidos como contra-estrategia a la revolución cubana. Como varios trabajos han demostrado (Benmergui, 2009), la influencia de la Alianza para el Progreso no se puede entender desde una asimilación y puesta en práctica en los territorios en dónde fue aplicada, sino desde una negociación con pautas y políticas preexistentes que mediaron su implementación. La modernización de América Latina siempre ha sido eso: un constante pacto entre diferentes fuerzas de origen y valencia disímiles. La historia de estas urbanizaciones no constituye una excepción: la necesidad heredada de los años del Estado Novo y el segundo mandato de Getúlio Vargas de relocalizar a los habitantes de las llamadas favelas, otorgándoles la posibilidad de acceder a una vivienda digna, coincidió con la injerencia local de la política hemisférica de la Alianza para el Progreso. Esta coincidencia de intereses locales y una tendencia supranacional creó un ímpetu constructor creador de espacios y fronteras. Así, a través de los programas de vivienda popular el sentido de la modernización y el desarrollo encontraba un escenario donde tomar forma.

En Rio de Janeiro esta intervención se dio durante el gobierno de Carlos Lacerda, cuya trayectoria política e historia personal constituyeron un trasunto fascinante en los años que siguieron al suicidio de Vargas. La iniciativa motivó la construcción de cuatro barrios de vivienda popular en el casco urbano de la ciudad: Vila Aliança, Vila Esperança, Vila Kennedy y Cidade de Deus. De esta manera, el origen de Bangú y Vila Aliança es paradigmático de los proyectos de vivienda que pulularon en la región durante los años sesenta: es decir, proyectos que, a partir de una idea de expansión del acceso a la propiedad de vivienda y condiciones decentes de vida, promulgaron "hábitos de clase media, consumo masivo y comportamiento político moderado" (Benmergui, 2009, p. 305). Sus habitantes llegaban desde las favelas que estaban siendo reubicadas bajo una lógica de modernización del territorio. Este proceso era el resultado de una amalgama de factores externos que entraban a ser negociados a partir de las dinámicas locales. En el caso de Rio de Janeiro, el llamado "populismo de clase media" de Carlos Lacerda (McCann, 2003, p. 661) otorgó el telón de fondo para que estas dinámicas se desarrollaran. 
Este tipo de proyectos se popularizó a lo largo y ancho de América Latina, llegando incluso a la repetición nominal: en Bogotá (Colombia), por ejemplo, la localidad más grande de la ciudad se llama precisamente Ciudad Kennedy. El facsímil no es sólo nominal: las mismas dinámicas sociales aquejan a todos los barrios por igual. Estas dinámicas están determinadas por la naturaleza periférica de las fundaciones y a la singular tensión que en su seno se escenificó entre las ansias de igualdad e inclusión que representaba el traslado de sus poblaciones originarias a un lugar pensado para que desarrollaran sus condiciones ciudadanas, y las dinámicas que niegan esa aspiración. Benmergui (2009, p. 305) deja claro cómo una parte fundamental de esta gramática ciudadana fue precisamente la postulación de una idea específica de clase media y de las prácticas cotidianas que sirven de correlato a ésta.

El Sarau do Velho se organiza en Bangú, en la parte occidental de Rio de Janeiro, una de las zonas más afectadas durante los últimos años por la violencia relacionada con el tráfico de droga y que ha visto la intervención del ejército como política gubernamental de control del territorio y sus poblaciones. Uno de los barrios originarios de la zona es precisamente Vila Aliança, en una de cuyas calles se realiza el evento. Como muchos de los saraus de la ciudad, el Sarau do Velho surgió después del año 2013 organizado por jóvenes que pertenecen o tienen vínculos de amistad con el colectivo cultural que organiza el Sarau do Escritório. Al igual que éste, las convocatorias para su asistencia se realizan públicamente a través de las redes sociales, especialmente Facebook.

La invitación del veinte de agosto de 2017 vincula la realización del evento con la historia urbana del barrio. Cada una de las calles originales tienen el nombre de una profesión liberal relacionada con una idea modernizadora del territorio: Rua Aviador, Rua Editor, Rua Granjeiro, etc. El sarau inscribe su escenificación en un teatro ya antiguo cuya gramática básica es la del desarrollo de la nación. La cuadrícula del barrio constituye un plano y un plan que encierra un modelo específico de país. En la actualidad, ese plan se intersecta con las dinámicas contemporáneas del territorio: en ese sentido las calles del barrio no se diferencian en lo esencial de las de cualquier vecindad periférica de América Latina. El evento mismo se realiza en las puertas de la tienda del barrio (boteco): Mr. Lanches, que se encuentra en la Rua do Orfeonista $\mathrm{n}^{\circ} 4$. Es significativo que el nombre de esta calle, denotando al miembro de un coro que no se acompaña con instrumentos, constituya el sitio en donde una intervención cultural tendiente a visibilizar el territorio tenga lugar. Este hecho comenta no solo cómo la fundación original del territorio tiene ecos en la manera en que aún éste es entendido y leído por sus habitantes, sino también hasta qué punto en la gramática del desarrollo y clase media que originó la fundación de los barrios se involucraba una idea específica de cultura. Después de medio siglo de ese momento fundacional, el mismo sitio y la misma gramática congregan a la comunidad y los organizadores del sarau a pesar de la amenaza de lluvia que presagian las nubes cargadas que se avecinan desde el norte.

Llegar a Bangú y específicamente a Vila Aliança toma tiempo. Son aproximadamente dos horas de viaje desde el centro de la ciudad. El traslado implica tomar un tren desde la mítica Estação Central y al menos un recorrido a las espaldas de uno de los cientos de moto-taxistas que prestan sus servicios en los barrios de la periferia. El barrio conserva los nombres originales de las calles, organizadas en la zona alrededor de un edificio que alberga una de las muchas iglesias evangélicas que pululan en el territorio. Pequeñas tiendas se ven repetidas a lo largo y ancho de las avenidas que forman la cuadrícula del barrio, junto a improvisados talleres mecánicos con carros antiguos aparcados en frente. Aunque es fin de semana, la calle presenta actividad y se ven personas en los andenes rumbo a sus casas o de camino a alguna de las tiendas abiertas a esa hora. El jolgorio de niños jugando se escucha en cada esquina. Al llegar en la moto y antes de bajarme y pagarle, mi conductor me preguntó preocupado si sabía para dónde iba, presagiando la presencia de un discurso que estaría presente durante toda mi estadía allí: el de la seguridad contrastada con la tradición de los valores.

En 2018, Bangú en general y Vila Aliança en particular fueron escenario del despliegue de las tropas del ejército como última estrategia de contención puesta en práctica por la municipalidad de Rio de Janeiro ante la ola de criminalidad relacionada con el micro-tráfico de 
drogas, es decir la venta de éstas al detal dentro de las comunidades. Este es un flagelo que no es ajeno a muchas ciudades en América Latina y se explica por el avance del consumo de drogas ilícitas en los territorios. Esto hace que el espacio sea disputado por las diferentes facciones que buscan controlar la venta de las substancias. De esta manera el territorio específico de Vila Aliança se convirtió en un laboratorio de la intervención de las fuerzas de seguridad en la ciudad. Retenes de policía militar fueron apostados en las entradas y salidas del barrio con el fin de controlar y empadronar a los habitantes y evitar la visita de personas ajenas al territorio. Esta estrategia significó el fin de la estrategia puesta en marcha por la implementación de las UPP (Unidade de Policía Pacificadora) y la vuelta a y consolidación del modelo de seguridad ejemplificado por el espacio dividido en la manera en que Teresa Caldeira (2000) caracteriza las dinámicas espaciales en que se traduce la democracia disyuntiva (Holston, 2008) del país.

Paradójicamente, esta vuelta a las políticas de seguridad que entienden el territorio como un recurso a ser controlado tiene eco en la conversación diaria de los habitantes del barrio, quienes inscriben su discurso de pertenencia al territorio a partir de la narrativa sobre criminalidad que permea la interpretación del espacio. Este lenguaje se inscribe en la historia de su barrio de una manera que comenta el espacio mismo del sarau. En la tarde de sábado durante la cual se celebra el evento, el Sarau do Velho se presenta de manera similar al Sarau do Escritório, con una programación continua de músicos, poetas y espontáneos que usan el escenario improvisado en la terraza donde vive la familia de uno de los organizadores.

Casi medio siglo después de su fundación, la historia del barrio se determina a partir de una identidad específica aparejada a un apego a la autenticidad del habitante original del territorio. Esto se deja traslucir en la conversación con el padre de uno de los organizadores del evento. Mientras la música desciende desde la terraza cubierta del segundo piso de la construcción, que se ha acondicionado como escenario provisional por la lluvia inesperada que empezó a caer desde el mediodía, el orgulloso hombre me cuenta que los habitantes originales del barrio eran todos gente buena, con "fundamento". Su hijo (el organizador del sarau), tiene también "fundamento", transmitido por él mismo. Y a eso le achaca la idea que éste tuvo de organizar el sarau mismo. "Fundamento" en este contexto se refiere a una educación moral incentivada por sus familias, acostumbrados a trabajar y a ganarse la vida de manera digna. Es evidente que quiere hacerme ver que la mala fama reciente sobre el barrio se debe a los foráneos, a personas extrañas a la mitología fundacional que no deben considerarse como habitantes por derecho propio del territorio. En su habla existen genealogías de habitantes originarios, aquellos que como él que llegaron de la favela o del nordeste para ver crecer a sus familias en medio de las calles del barrio y el esfuerzo personal de sus habitantes. Los demás, relacionados de inmediato con las actividades criminales que pululan en las noticias, no pueden ser considerados por derecho propio como vecinos del territorio.

Esta visión genealógica que se compadece con la mitología clasemediera con que fueron fundados los barrios, se enlaza de manera directa con la organización del sarau como herramienta de revitalización del espacio. La genealogía de auténticos moradores del territorio se opone al discurso sobre criminalidad que permea la narrativa contemporánea del barrio y comenta la implementación de la política de seguridad puesta en marcha por la presencia de la policía militar. A través del habla del padre y poblador originario, la realidad del sarau y el discurso de seguridad se entrelazan en una sola gramática donde el emprendimiento y la autenticidad forman parte del mismo discurso. Es muy significativo que el empadronamiento puesto en marcha por la policía militar haya tenido el fin último de identificar a los moradores reales del espacio, convirtiéndose en una escenificación práctica del discurso de autenticidad enunciado por el padre del organizador del sarau. Esta intervención se convierte en paradigmática del tipo de intervenciones en donde la periferia es usada como facsímil del derecho a tener un "sueño propio" y comenta las intervenciones mencionadas en páginas anteriores cuando se mencionó el caso del Sarau do Escritório: el rescate del territorio se da a partir de unos marcadores de clase cuya valencia está determinada por la posición de la cultura en relación con un modelo aspiracional dado. 
El sarau se inscribe así en una genealogía del desarrollo que se manifiesta en la manera en que la escenificación de la cultura se enlaza con un territorio que desde sus inicios ha negociado su pertenencia a la urbe. En esta tensión negociadora el concepto de autenticidad siempre ha jugado el papel de mediador que determina la pertenencia a esa tradición. Esta versión de urbanidad, al mismo tiempo, se relaciona con unos valores que han sido identificados como pertenecientes a la clase media (Benmergui, 2009) y cuya presencia en la escenificación del Sarau do Velho se enmarca con lo que Lucia Tennina (2017, p. 101) identifica como las fallas de una cultura periférica que no puede escapar a la tradición en la que se enmarca y por lo tanto a las contradicciones y limitaciones de su papel en el ansia modernizadora de la nación. Tal como Tennina lo deja ver en su escrito, muchas veces a la cultura se le otorga la responsabilidad de "funcionar como solución social a gran escala" sin emprender los cambios estructurales que son necesarios para propender por una sociedad más justa. La cultura entonces termina enmarcada dentro de una política de inserción más que de integración. El ansia aspiracional de la periferia no deslegitima su esfuerzo, sino que lo contextualiza en la gramática más grande del desarrollo y de tal manera permite entender mejor sus dinámicas. De esta manera los contornos del espacio ciudadano se revelan porosos y maleables, determinados por coordenadas impuestas desde diferentes tiempos y locales, una frontera en permanente negociación y siempre al límite de los contornos impuesto por un modelo antagonista de democracia. A este estado de cosas los espacios como el Sarau do Velho contraponen un modelo estratégico que devela el entramado hegemónico de su existencia agonista.

\section{Conclusiones}

Los saraus tratados en este artículo ofrecen un repertorio limitado pero representativo de las formas en que las estrategias de reclamación de derechos inspiradas por la Constitución del 88 adoptaron una gramática otorgada por tradiciones fabricadas desde la imaginación económica de los territorios. Las subjetividades ciudadanas escenificadas y los espacios reclamados constituyen un espacio que contrasta las lecturas emprendidas hasta ahora desde la producción académica sobre el tema. Propongo que la discusión sobre el significado contemporáneo de los saraus como manifestación significativa del modelo cultural planteado por el Partido dos Trabalhadores puede enriquecerse a partir de un giro conceptual que entienda su aparición y existencia como monumentos portadores de unos significados y valencias dadas que vinculan su existencia con las reclamaciones democráticas del pasado. Estas reclamaciones no sólo incluyen el lenguaje de derechos instaurado por la Constitución del 88 sino también el postulado por una tradición del desarrollo económico en donde las clases medias juegan un papel fundamental. Este punto de vista complementa el análisis de los saraus y el de sus subjetividades ciudadanas como documentos del presente articulados sólo a partir de la reclamación de derechos. El giro desde el sarau documento hacia el sarau monumento (como portador de una tradición) permite adoptar una visión compleja de su postulación a partir del involucramiento de una genealogía del desarrollo que siempre ha servido como correlato inevitable y problemático de la democracia brasilera.

De ninguna manera esta discusión se limita al espacio cultural propuesto por los saraus, tanto el Sarau do Escritorio y el Sarauo do Velho comentan en sus espacios de postulación el tipo de subjetividades políticas que determinarán el principio del siglo XXI brasilero. Sin conocer el resultado de las elecciones presidenciales del 2018, por ejemplo, es evidente que cualquiera que sea el resultado, la visibilidad del candidato Jair Bolsonaro es el evento político más importante de los últimos años en el país. Las formas en que su discurso se imbrica con una red de significados forjados desde el emprendimiento individual, la importancia de la tradición y la tensión incesante entre la periferia y la urbe tiene mucho más que ver con el modelo de país propuesto por el Partido dos Trabalhadores que lo que la producción académica ha estado dispuesta a admitir.

En últimas, la reinterpretación propuesta de los saraus como espacios monumentales comenta sus posibilidades ciudadanas desde lo que Chantal Mouffe propone como un modelo agonista de lo político: es decir, uno en donde la confrontación con el otro/enemigo se desplace 
desde el eje de la eliminación física al del adversario cuya existencia es legítima y legitimizadora del espacio político. Esta relación entre adversarios es re-imaginada como un intercambio cuyo telón de fondo es siempre un modelo hegemónico heredado. El imbricamiento en la escena de los saraus comentados entre la cultura como reivindicación de la periferia y su sustrato en una genealogía del desarrollo, convierte a estos espacios en un laboratorio de democracia que se encuentra en permanente tensión entre las confrontaciones puntuales a cierto modelo de dominación, y el uso estratégico de herramientas y marcadores para encarar el conflicto. Es en estas tensiones y en las subjetividades que representan, más que en la reivindicación de una u otra identidad en un contexto dado en donde se encuentra el eje democrático del territorio. Dicho de otra manera: los saraus son el escenario mismo de la confrontación agónica de la política en el Brasil contemporáneo no porque le den voz a una u otra posición o identidad sino porque en su configuración, naturaleza y adaptabilidad se encierra la contradicción misma de la acción agónica. Es su inestabilidad lo que propone una vía hacia adelante de la lucha por la ciudadanía y constituye una metonimia de la naturaleza política de la periferia.

Ésta, al igual que los saraus, se encuentra atravesada por contradicciones que amenazan los avances democráticos más fácilmente percibidos en los últimos años. Los saraus contemplados permiten comprender en su escenificación algunas de las tensiones características de la lucha por la democracia desde la promulgación de la constitución del 88. En el caso del Sarau do Escritório la implicación de la gramática del emprendimiento sirve como herramienta estratégica para reivindicar el espacio urbano de un barrio abandonado por la ciudad. En este caso la periferia como idea es usada como pieza estratégica de confrontación. En un movimiento opuesto pero equivalente, El Sarau do Velho apela a la tradición desarrollista y a un prurito de la tradición barrial para inscribir el sarau como un gesto reivindicatorio de su espacio periférico. Los dos constituyen un ámbito en el que las contradicciones y posibilidades de la democracia en un contexto como el del Brasil contemporáneo son reincorporadas y reinterpretadas en el mismo gesto.

\section{Bibliografía}

BEAL, Sophia (2013). Brazil under construction: fiction and public works. New York: Palgrave MacMillan.

BENMERGUI, Leandro (2009). The alliance for progress and housing policy in Rio de Janeiro and Buenos Aires in the 1960s. Urban History, v. 36, n. 2, p. 303-326.

CALDEIRA, Teresa Pires do Rio (2000). City of walls: crime, segregation, and citizenship in São Paulo. Berkeley: University of California Press.

CHAMONE, Aline Maria Macedo (2016). Um estudo sobre os saraus da periferia de São Paulo: espaços para "aprender na amizade e na liberdade". Dissertation (Maestría en Educación) - Universidad de São Paulo, São Paulo.

DAGNINO, Evelina (2005). "We all have rights, but..." Contesting concepts of citizenship in Brazil. In: KABEER, Naila. Inclusive citizenship: meanings and expressions. London: Zed. p. 149-163.

DALCASTAGNÈ, Regina (2014). Deslocamentos urbanos na literatura brasileira contemporânea. Journal for Brazilian Studies, v. 3, n. 1, p. 31-47.

HOLSTON, James (2008). Insurgent citizenship: disjunctions of democracy and modernity in Brazil. Princeton: Princeton University Press.

LEHNEN, Leila (2016). Literatura e direitos humanos na obra de Sacolinha. Estudos de Literatura Brasileira Contemporânea, Brasília, n. 49, p. 79-104, dic.

LEHNEN, Leila (2018). O direito à poesia. In: DALCASTAGNÈ, Regina; DUTRA, Paula; FREDERICO, Graziele (Org.). Literatura e direitos humanos. Porto Alegre: Zouk.

LEHNEN, Leila Maria (2013). Citizenship and crisis in contemporary Brazilian literature. New York: Palgrave MacMillan. 
MCCANN, Bryan (2003). Carlos Lacerda: the rise and fall of a middle-class populist in 1950s Brazil. Hispanic American Historical Review, n. 4, p. 661.

NASCIMENTO, Erica Peçanha do (2009). Vozes marginais na literatura. Rio de Janeiro: Aeroplano.

OLIVEIRA, Rejane Pivetta de; PELLIZZARO, Tiago (2017). Literature and the sarau: political implications. Abriu: Textuality Studies on Brazil, Galicia and Portugal, n. 6, p. 65-83.

PANTOJA, Fabio Zambrano (2002). De la Atenas suramericana a la Bogota moderna. Revista de Estudios Sociales, n. 11, p. 26.

PEREIRA, Anthony W.; MATTEI, Lauro (2015). The Brazilian economy today: towards a new socio-economic model? New York: Palgrave Macmillan.

RAMA, Angel (1984). La ciudad letrada. Hanover: Ediciones del Norte.

ROBBINS, Bruce (2007). Upward mobility and the common good: toward a literary history of the Welfare State. Princeton: Princeton University Press.

SOUZA, Jessé; ARENARI, Brand (2010). Os batalhadores brasileiros: nova classe média ou nova classe trabalhadora?. Belo Horizonte: Editora da UFMG.

TENNINA, Lucía (2014). Brasil periférico: literatura marginal de São Paulo. Ciudad de México: Secretaría de Cultura.

TENNINA, Lucía (2017). The deterritorialization and internationalization of the saraus in the periphery of São Paulo. Abriu: Textuality Studies on Brazil, Galicia and Portugal, Barcelona, n. 6, p. 85-103.

VAZ, Sérgio (2008). Cooperifa: antropofagia periférica. Rio de Janeiro: Aeroplano.

WALLERSTEIN, Immanuel (1988). The Bourgeois(ie) as concept and reality. New Left Review, n. 167, p. 91.

YOUNG, Iris Marion (1990). Justice and the politics of difference. Princeton: Princeton University Press. 